\title{
DORMÊNCIA E DESENVOLVIMENTO DE SEMENTES DE SABIÁ (Mimosa caesalpiniifolia Benth.) $)^{1}$
}

\author{
Edna Ursulino Alves², Rubens Sader ${ }^{2}$, Riselane de Lucena Alcântara Bruno ${ }^{3}$, Adriana Ursulino Alves ${ }^{4}$
}

\begin{abstract}
RESUMO - O objetivo desta pesquisa foi estudar o estabelecimento da dormência nas sementes de sabiá (Mimosa caesalpiniifolia Benth.) durante o processo de maturação. Foram realizadas 16 colheitas semanais de frutos e sementes, na localidade de Engenho Bujari, município de Areia, PB, no período de 9 de agosto a 22 de novembro de 2001. As colheitas ocorreram aos 105 dias após a antese (d.a.a.) e se estenderam até os 210 d.a.a., sendo avaliadas as porcentagens de germinação, sementes dormentes, vigor (primeira contagem de germinação, comprimento e massas fresca e seca das plântulas). Concluiu-se que a colheita deverá ser efetuada aos 154 d.a.a., quando a germinação se apresenta com aproximadamente $80 \%$ e o acúmulo de massa seca nas sementes atinge o máximo.
\end{abstract}

Palavras-chave: maturação, germinação, vigor, sementes florestais.

\section{DORMANCY AND DEVELOPMENT IN "SABIÁ" (Mimosa caesalpiniifolia Benth.) SEEDS}

\begin{abstract}
The objective of this research was to study the dormancy of Mimosa caesalpiniifolia Benth. seeds during the maturation process. The seeds and fruits were collected from plants in a locality called Engenho Bujari, city of Areia, State of Paraíba, Brasil. Seed harvest extended from the $105^{\text {th }}$ day after anthesis (d.a.a.) to the $210^{\text {th }}$ (d.a.a.), from August 9 to November 22, 2001. The parameters evaluated were germination $\%$, dormancy (\%), vigor expressed by the first germination (\%), seedling length, and seedling fresh and dry weight. It is concluded that to avoid seed dormancy in this species the collection must be done 154 d.a.a., when germination and accumulation of dry mass is maximum.
\end{abstract}

Key words: maturation, germination, vigor and forest seeds.

\section{INTRODUÇÃO}

O sabiá (Mimosa caesalpiniifolia Benth.) é uma planta pioneira, decídua, heliófita, com ocorrência preferencial em solos profundos, tanto em formações primárias quanto secundárias (LORENZI, 2000). Nativa da região Nordeste do Brasil, pertence à família Mimosaceae, sendo conhecida também como sabiá ou sansão-do-campo (RIBEIRO, 1984). A árvore apresenta características ornamentais, e sua madeira é apropriada para usos externos, como mourões, estacas, postes, lenha e para carvão. As folhas são utilizadas como fonte de alimento para o gado, especialmente durante a época seca no semi-árido. O sabiá é também muito utilizado como cerca viva, por ser pioneira, sendo ideal para recomposição de áreas degradadas (LORENZI, 2000).

\footnotetext{
${ }^{1}$ Recebido para publicação em 01.9.2003 e aceito para publicação em 10.8.2004.

${ }^{2}$ Departamento de Produção Vegetal, FCAV/UNESP, Via de Acesso Prof. Paulo Donato Castellane, s/n, 14.884-900 JaboticabalSP.E-mail: <eudalves@fcav.unesp.br>e <rsader@fcav.unesp.br>.

${ }^{3}$ Departamento de Fitotecnia - CCA-UFPB, Areia, PB. E-mail: <lane@cca.ufpb.br>.

${ }^{4}$ CCA-UFPB, Areia, PB. E-mail: <aualves@mailbr.com.br>.
} 
Bêde et al. (1985) relataram que as pastagens naturais no Nordeste podem ser substancialmente melhoradas pelo uso adequado de leguminosas arbóreas com alto valor protéico e capacidade de suporte. Para essa finalidade, Almeida et al. (1986) comentaram que a Mimosa caesalpiniifolia Benth., por ser uma espécie nativa da região semi-árida, constitui-se numa das leguminosas arbóreas com grande potencial, devido a sua resistência a estiagens prolongadas, crescimento rápido e alto teor protéico das folhas.

O sabiá é empregado na proteção e delimitação de pomares na citricultura, em razão da sua grande quantidade de acúleos. No entanto, apesar de seu emprego ser freqüente ao redor, ainda não há levantamento sobre a extensão de seu uso ou das regiões que preferencialmente o adotam (LARANJEIRA, 1997).

A propagação dessa espécie é via sementes, no entanto estas apresentam dormência e, por ocasião da dispersão natural, ocorrem grandes perdas devido à disseminação dos craspédios, designados por pequenos segmentos unisseminados, os quais formam a vagem (fruto).

As sementes de muitas espécies florestais tropicais germinam rapidamente desde que estejam maduras (ALEXANDRE, 1980 citado por MOUSSA et al., 1998). No entanto, espécies com sementes duras podem permanecer dormentes por muitos anos (CARPENTER et al., 1993). Baseando-se em espécies tropicais, Sasaki (1980ab) relatou que os tegumentos duros das sementes dessas espécies estão freqüentemente cobertos por uma cutícula cerosa que impede a embebição de água e são altamente impermeáveis à difusão de oxigênio. Kozlowski et al. (1991) acrescentaram que esses tegumentos duros oferecem alta resistência física para o crescimento do embrião.

Essas espécies com tegumento duro representam, freqüentemente, problemas consideráveis aos viveiristas interessados numa germinação rápida e uniforme (SANCHEZ-BAYO e KING, 1994; TEKETAY, 1994). Entretanto, enquanto se pensa que a impermeabilidade da cobertura é o principal empecilho à germinação das sementes, é possível que fatores endógenos também possam limitar a capacidade fisiológica do embrião e, assim, reduzir a germinação (MOUSSA et al., 1998).

A dormência é o fenômeno pelo qual sementes de determinada espécie, mesmo sendo viáveis e ten- do todas as condições ambientais para tanto, não germinam. $\mathrm{O}$ fenômeno da dormência é tido como um recurso pelo qual a natureza distribui a germinação no tempo (FOWLER e BIANCHETTI, 2000; FOWLER e MARTINS, 2001). Koller (1972) e Carvalho e Nakagawa (2000) comentaram que a dormência é tida, também, como um mecanismo que funciona como uma espécie de "sensor remoto", o qual controlaria a germinação de modo que essa viesse a ocorrer não somente quando as condições fossem propícias à germinação, mas também ao crescimento da planta resultante.

Também, Veasey et al. (2000) relataram que a dormência de sementes é um fator importante na dinâmica de populações naturais e está relacionada à adaptação dos indivíduos a ambientes heterogêneos. Esses autores acrescentaram que essa variabilidade presente na natureza é importante para a própria sobrevivência dessas populações. De acordo com Baskin e Baskin (1985) e Bewley e Black (1985), a dormência garante que a germinação das sementes e, conseqüentemente, o desenvolvimento das plântulas ocorram na época e local mais adequados.

Apesar de reconhecer às desvantagens da dormência, Tao (1992) relatou ser esta uma característica de relativa importância em lotes de sementes de espécies cultivadas, por evitar que elas germinem nos frutos a campo em virtude do elevado teor de água.

A impermeabilidade do tegumento à água é um tipo de dormência bastante comum em sementes das famílias Leguminosae, Solanaceae, Malvaceae, Chenopodiaceae, Geraniaceae, Convolvulaceae e Liliaceae (POPINIGIS, 1985). De acordo com Rolston (1978), das 260 espécies de leguminosas examinadas, cerca de $85 \%$ apresentavam sementes com tegumento total ou parcialmente impermeável à água.

Nas sementes de Enterolobium contortisiliquum (Vell.) Morong, o aparecimento da dormência, pela impermeabilização do tegumento começou a ocorrer a partir da quarta colheita, dificultando a entrada de umidade, a qual repercutiu na inibição da porcentagem de germinação das sementes no teste de germinação (BORGES et al., 1980).

Em estudos realizados em Piracicaba, SP, com sementes de urucum (Bixa orellana L.), Amaral et al. (2000) observaram que as sementes começaram a germinar nos estádios E4 (sementes com forma obvóide, co- 
loração vermelho brilhante e teor de água de aproximadamente $77 \%$ ) e, neste como também no estádio E5 (sementes com forma cuneiforme, coloração vermelho-escura opaca e teor de água em torno de 56\%), a germinação foi máxima e, a partir daí, ocorreu sua redução. Os referidos autores acrescentaram que no estádio E7 (sementes com forma cuneiforme, coloração vermelho-escura opaca e teor de água em torno de $10,4 \%$ ) as sementes estavam completamente maduras e a germinação foi muito baixa, porque o tegumento da maioria das sementes já estava totalmente impermeável, impedindo a entrada de água. Veasey et al. (2000), estudando a maturação de sementes de Sesbania, verificaram grande variação na intensidade de dormência entre e dentro das espécies avaliadas e entre famílias (progênies de plantas individuais). Assim e diante da escassez de informações sobre a espécie Mimosa caesalpiniifolia Benth., o objetivo da presente pesquisa foi estudar o estabelecimento da dormência nas sementes durante o processo de maturação.

\section{MATERIAL E MÉTODOS}

O experimento de campo foi conduzido entre abril e novembro de 2001, em área de aproximadamente quatro hectares, de vegetação nativa de sabiá (Mimosa caesalpiniifolia Benth.) localizada na propriedade Engenho Bujari, no município de Areia, PB. Os tes- tes de germinação e vigor foram realizados no Laboratório de Análise de Sementes do Centro de Ciências Agrárias da Universidade Federal da Paraíba (CCA - UFPB), Campus de Areia, PB, situado a 574,62 m de altitude, 6 58' 12' S de latitude e 35'42'15' WGr. Conforme a classificação bioclimática de Gaussem, nessa área predomina o bioclima 3dth nordestino sub-seco, com precipitação pluviométrica média anual em torno de $1.400 \mathrm{~mm}$. Durante a condução do experimento foram coletados dados médios mensais referentes a temperatura máxima (Tx), média (Tm) e mínima (Tn) do ar, precipitação pluviométrica e umidade relativa do ar (Tabela 1).

\subsection{Marcação das inflorescências}

Foram demarcados mais de 100 indivíduos, os mais vigorosos e com boa aparência fitossanitária, com altura de quatro a oito metros, com idade de aproximadamente 10 anos. Na segunda quinzena de abril, após se constatar que $50 \%$ das inflorescências das árvores selecionadas se encontravam em antese, procedeu-se à marcação dessas inflorescências, na copa das árvores, utilizando fios de lã.

\subsection{Colheita de frutos e sementes}

As colheitas de frutos de Mimosa caesalpiniifolia Benth. foram iniciadas aos 105 dias, estendendo-se até os 210 dias após a antese. Foram realizadas a cada

Tabela 1 - Temperaturas máxima (Tx), média (Tm) e mínima (Tn), precipitação e umidade relativa do ar, 2001 Table 1 - Maximum temperature (Tx), average (Tm) and minimum (Tn), precipitation and relative humidity of the air, 2001

\begin{tabular}{cccccc}
\hline $\begin{array}{c}\text { Meses } \\
\text { do Ano }\end{array}$ & Tx & $\begin{array}{c}\text { Temperatura do Ar* } \\
\text { Tm }\end{array}$ & Tn & $\begin{array}{c}\text { Umidade Relativa } \\
\text { do Ar* } \\
\text { \% }\end{array}$ & $\begin{array}{c}\text { Precipitação* } \\
\text { m m }\end{array}$ \\
\hline Jan & & C & & 81 & 46,6 \\
Fev & 28,1 & 22,7 & 19,9 & 76 & 19,7 \\
Mar & 30,5 & 23,9 & 20,5 & 83 & 175,1 \\
Abr & 28,8 & 23,4 & 20,6 & 88 & 155,3 \\
Mai & 27,1 & 22,6 & 20,1 & 83 & 10,5 \\
Jun & 28,1 & 23,0 & 20,3 & 89 & 235,1 \\
Jul & 24,9 & 21,3 & 19,1 & 90 & 160,8 \\
Ago & 24,2 & 20,7 & 18,6 & 84 & 139,6 \\
Set & 24,5 & 20,3 & 17,8 & 84 & 65,3 \\
Out & 26,6 & 21,4 & 18,7 & 80 & 21,3 \\
Nov & 28,2 & 22,6 & 19,8 & 81 & 20,8 \\
Dez & 28,6 & 23,1 & 20,3 & 82 & 62,7 \\
Total acumulado & 28,9 & 23,5 & 20,8 & - & 1112,8 \\
\hline
\end{tabular}

* Levantamento da Estação Meteorológica do CCA - UFPB, Areia,PB. 
sete dias, manualmente, com o auxílio de tesoura de poda, tomando-se o cuidado para não provocar injúrias mecânicas nos frutos e nas sementes. Imediatamente após a colheita, amostras de frutos e sementes foram acondicionadas em embalagens plásticas, identificadas e encaminhadas ao Laboratório de Análise de Sementes do Centro de Ciências Agrárias da Universidade Federal da Paraíba, dentro de caixas térmicas, para evitar que ocorressem alterações no teor de água. O percurso entre o campo experimental e o laboratório era de aproximadamente cinco quilômetros.

Ao longo do experimento, foram realizadas 16 colheitas de frutos, iniciando-se a primeira no dia 09.08.2001, sendo a última em 22.11.2001.

\subsection{Determinações Efetuadas}

\subsubsection{Teste de germinação}

Após cada colheita, uma amostra de frutos foi colocada à sombra para secar por oito dias; posteriormente, as sementes foram extraídas manualmente e utilizadas nos testes de germinação. Quando os frutos e sementes foram colhidos com a coloração marrom, as sementes foram extraídas e semeadas logo após a chegada ao laboratório.

Os testes de germinação foram instalados em caixas plásticas transparentes de $11 \times 11 \times 3 \mathrm{~cm}$, com tampa, contendo, como substrato, duas folhas de papel-filtro na base e uma na parte superior cobrindo as sementes. Após o semeio, as caixas foram postas em germinador tipo B.O.D., regulado à temperatura alternada de 20-30 ${ }^{\circ} \mathrm{C}$ e fotoperíodo de oito horas, com oito amostras de 25 sementes. As contagens foram realizadas no terceiro (MARTINS et al., 1992) e décimo dias (TORRES et al., 1994) após a semeadura. Para superação da dormência, foram conduzidos testes de germinação com sementes que sofreram pequeno corte (desponte), com o auxílio de uma tesoura pequena, na região oposta à da emissão da radícula.

\subsubsection{Testes de vigor}

\subsubsection{Primeira contagem de germinação}

Conduzida computando-se a porcentagem de plântulas que apresentaram raiz primária $\geq 3 \mathrm{~cm}$. As contagens foram realizadas no terceiro dia após a semeadura, conforme recomendações de Martins et al. (1992).

R. Árvore, Viçosa-MG, v.28, n.5, p.655-662, 2004

\subsubsection{Comprimento de plântulas}

No final do teste de germinação, o hipocótilo e a raiz primária das plântulas normais de cada repetição foram medidos com o auxílio de régua graduada, com os resultados expressos em centímetros por plântula.

\subsubsection{Massa fresca e seca de plântulas}

Depois de concluído o teste de germinação, as plântulas normais de cada repetição, após a retirada dos cotilédones, foram pesadas, e em seguida colocadas em estufa de ventilação forçada a $80^{\circ} \mathrm{C}$, por 24 horas. Decorrido esse período, as plântulas foram retiradas da estufa, colocadas em dessecadores e, em seguida, pesadas em balança analítica com precisão de 0,001 g, com os dados expressos em g/plântula (NAKAGAWA, 1999).

\subsection{Delineamento estatístico}

O delineamento estatístico foi o inteiramente casualizado, com os dados submetidos à análise de variância; e as médias comparadas entre si, pelo teste de Tukey a $5 \%$ de probabilidade.

\section{RESULTADOS E DISCUSSÃO}

\subsection{Germinação e dormência das sementes}

Os dados referentes à germinação encontram-se na Figura 1. Observou-se que dos 126 aos 154 dias após a antese não houve diferença estatística na porcentagem de germinação das sementes com e sem tratamento pré-germinativo, indicando que nesse período não houve influência da dormência no processo germinativo.

A partir dos 154 dias após a antese, verificouse aumento na intensidade de dormência nas sementes de Mimosa caesalpiniifolia Benth., sendo esta manifestada através de redução drástica e gradativa da porcentagem de germinação das sementes que não foram submetidas a tratamento pré-germinativo, as quais diferiram estatisticamente daquelas sementes com tratamento pré-germinativo até o final do período de avaliação (210 d.a.a.). Dessa forma, as sementes colhidas aos 154 d.a.a. dispensam os tratamentos pré-germinativos.

No período em que se registraram os maiores porcentuais de germinação nas sementes sem tratamento pré-germinativo, o teor de água dos frutos e 
das sementes se encontrava elevado.

$\mathrm{Na}$ época em que se constatou redução acentuada na porcentagem de germinação das sementes que não foram submetidas a tratamentos pré-germinativos e, proporcionalmente, aumento na porcentagem de sementes duras ocorreu elevação na temperatura e redução na precipitação (Tabela 1), fato esse que submeteu as sementes a um estresse, com conseqüente aumento da dormência tegumentar. Muitas espécies leguminosas, como é o caso do sabiá, desenvolvem naturalmente a impermeabilidade do tegumento, diminuindo a umidade das sementes, como mecanismo de mantê-las viáveis por períodos longos (WILLAN, 1985).

Resultados semelhantes foram obtidos por Borges et al. (1980) ao estudarem a maturação e dormência de sementes de Enterolobium contortisiliquum (Vell.) Morong, em que verificaram que o aparecimento da dormência, através da impermeabilização do tegumento, ocorreu a partir da quarta colheita, o que dificultou a entrada de água e a germinação das sementes.

Também, Amaral et al. (2000) observaram os menores porcentuais de germinação em sementes de Bixa orellana L. quando as estas estavam completamente maduras, época em que o tégmen da maioria delas se encontrava completamente impermeável, impedindo, assim, a entrada de água. No entanto, Barbosa et al. (1992) constataram que as porcentagens de sementes dormentes de Copaifera langsdorffii Desf. aumentavam até os 154 dias após o florescimento, diminuindo com a evolução da maturação e atingindo valores mínimos aos 203 dias, ocasião em que o teor de água das sementes se encontrava em declínio e próximo da máxima massa seca.

\subsection{Vigor e dormência de sementes}

\subsubsection{Primeira contagem de germinação}

De acordo com os dados da Figura 2, verificouse a influência da dormência na primeira contagem de germinação desde o início (126 dias após a antese) até o final (210 dias após a antese) do período de avaliação, em que ocorreram diferenças significativas entre as sementes, sem tratamento, e aquelas submetidas a tratamento pré-germinativo, sendo os maiores porcentuais de germinação obtidos com as sementes submetidas ao desponte (Figura 2).

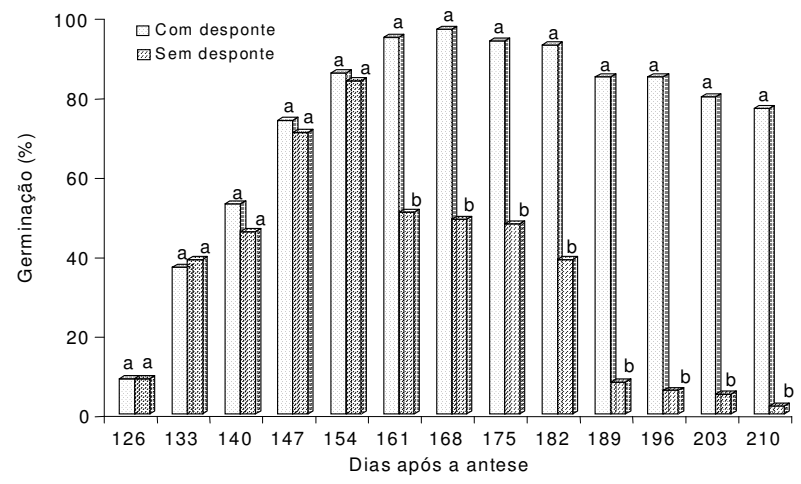

Figura 1 - Germinação de sementes das Mimosa caesalpiniifolia Benth. colhidas em diferentes épocas, com e sem desponte.

Figure 1-Germination of the Mimosa caesalpiniifolia Benth. seeds collected in different stages of development, with and without blunts.

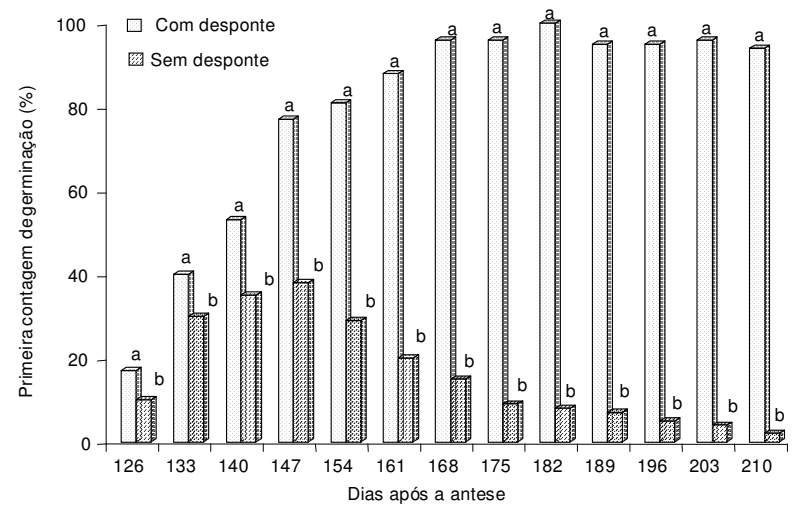

Figura 2 - Vigor das sementes de Mimosa caesalpiniifolia Benth. colhidas em diferentes épocas, com e sem desponte.

Figure 2 - Vigour of Mimosa caesalpiniifolia Benth. seeds collected in different stages of development, with and without blunts.

Comportamento semelhante foi descrito das sementes de Ilex paraguariensis A. St. -Hil., as quais foram classificadas como duras por Fowler e Sturion (2000), o que as torna impermeáveis, dificultando a absorção de água, as trocas gasosas e, conseqüentemente, a germinação. Barbosa et al. (1992) comentaram que a variação e o aumento na porcentagem de sementes germinadas de Copaifera langsdorffii Desf. aconteceram, principalmente, devido à evolução da maturidade fisiológica e não a substâncias inibidoras da germinação das sementes.

R. Árvore, Viçosa-MG, v.28, n.5, p.655-662, 2004 


\subsubsection{Comprimento da raiz primária e do hipocótilo}

Os dados apresentados nas Figuras 3 e 4 referem-se ao comprimento da raiz primária e do hipocótilo, respectivamente, das sementes com e sem tratamento pré-germinativo. Através dos dados, constatou-se que as poucas sementes que germinaram no tratamento sem desponte apresentaram comprimento da raiz primária um pouco menor que as plântulas originadas de sementes que foram despontadas.

A diferença no comprimento da raiz primária evidenciou-se a partir dos 147 dias após a antese, quando os maiores valores foram obtidos nas plântulas oriundas de sementes submetidas ao desponte e assim permanecendo até o final do período de avaliação (210 dias após a antese). As plântulas originadas de sementes não submetidas a tratamento pré-germinativo apresentaram os menores valores dessa característica (Figura 3). Com relação ao comprimento do hipocótilo, não se verificou influência da dormência sobre essa variável (Figura 4).

\subsubsection{Massas fresca e seca de plântulas}

De acordo com os dados apresentados na Figura 5, referentes à massa fresca das plântulas, à semelhança do comprimento do hipocótilo não se verificou influência da dormência sobre essa característica, já que só puderam ser avaliadas as plântulas das

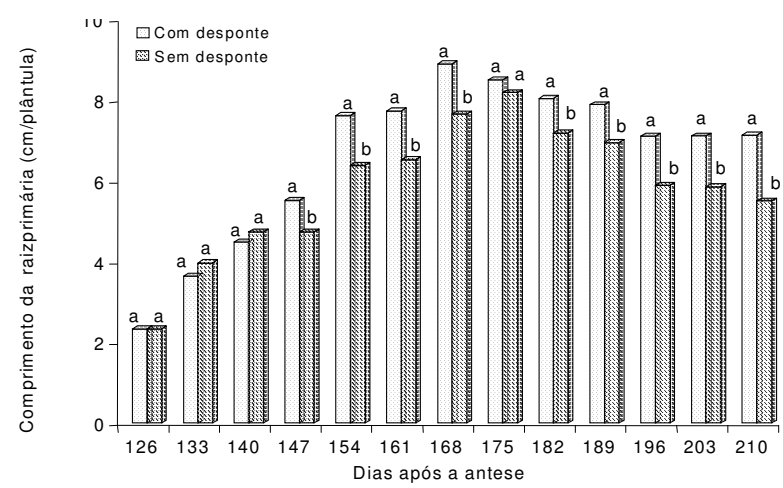

Figura 3 - Comprimento da raiz primária das plântulas de Mimosa caesalpiniifolia Benth. das sementes colhidas em diferentes épocas, com e sem desponte.

Figure 3-Length of the primary root of Mimosa caesalpiniifolia Benth. seedlings from seeds collected in different stages of development, with and without blunts. sementes que germinaram. Em contrapartida, observou-se que a dormência influenciou a massa seca das plântulas. A diferença foi verificada a partir dos 182 dias após a antese, estendendo-se até os 210 d.a.a., quando os maiores valores foram obtidos nas plântulas originadas de sementes submetidas ao desponte (Figura 6).

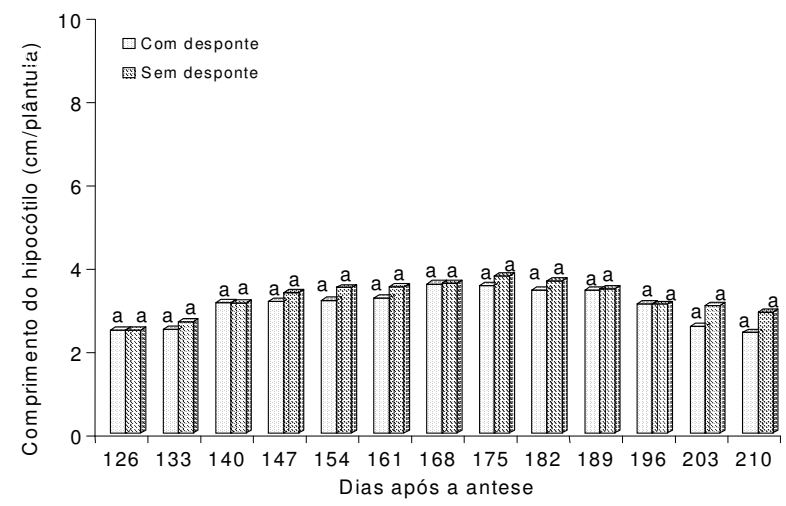

Figura 4-Comprimento do hipocótilo das plântulas de Mimosa caesalpiniifolia Benth. das sementes colhidas em diferentes épocas, com e sem desponte.

Figure 4-Length of the hypocotyl of Mimosa caesalpiniifolia Benth. seedlings from seeds collected in different stages of development, with and without blunts.

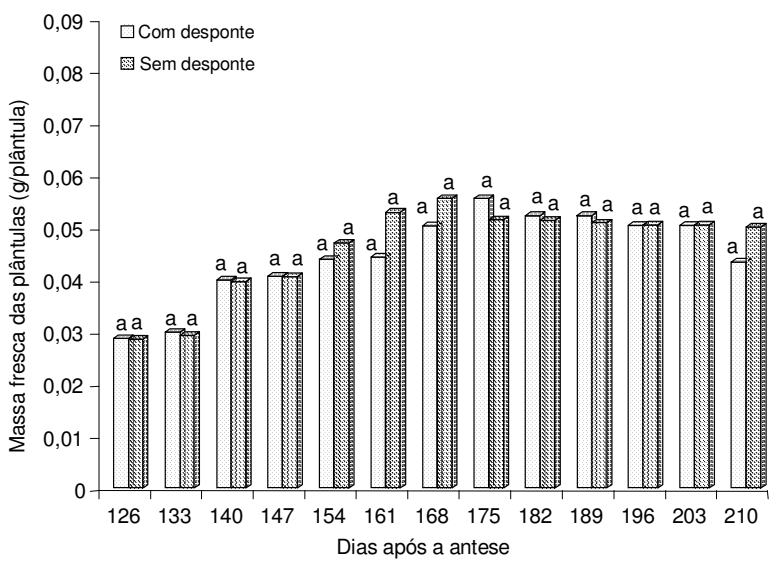

Figura 5 - Conteúdo de massa fresca das plântulas de Mimosa caesalpiniifolia Benth. de sementes colhidas em diferentes épocas, com e sem desponte.

Figure 5 - Fresh mass content of the Mimosa caesalpiniifolia Benth. seedlings from seeds collected in different stages of development, with and without blunts. 


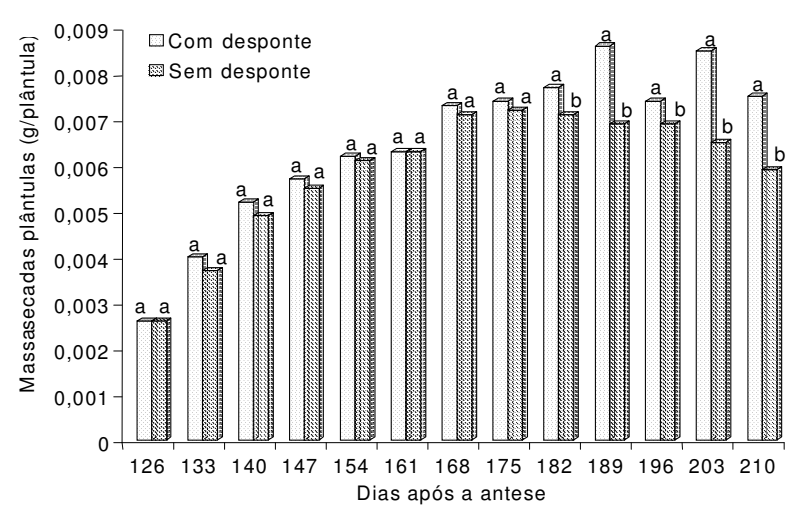

Figura 6 - Conteúdo de massa seca das plântulas de Mimosa caesalpiniifolia Benth. das sementes colhidas em diferentes épocas, com e sem desponte.

Figure 6-Dry mass content of the Mimosa caesalpiniifolia Benth. seedlings from seeds collected in different stages of development, with and without blunts.

\section{CONCLUSÃO}

A colheita dos frutos de Mimosa caesalpiniifolia Benth. pode ser efetuada aos 154 dias após a antese, com germinação das sementes em torno de $80 \%$ e acúmulo máximo de massa seca, ressaltando-se que a secagem em excesso dessas sementes podem induzi-las à dormência.

\section{REFERÊNCIAS BIBLIOGRÁFICAS}

ALMEIDA, R.T.; VASCONCELOS, I.; NESS, R.L.L. Infecção micorrízica vesículo-arbuscular e nodulação de leguminosas arbóreas do Ceará, Brasil. Ciência Agronômica, v.17, n.1, p.8997, 1986.

AMARAL, L.I.V.; PEREIRA, M.F.D.A.; CORTELAZZO, A.L. Germinação de sementes em desenvolvimento de Bixa orellana. Revista Brasileira de Fisiologia Vegetal, v.12, n.3, p.273-285, 2000.

BARBOSA, J.M.; AGUIAR, I.B.; SANTOS, S.R.G. Maturação de sementes de Copaifera langsdorffii Desf. Revista do Instituto Florestal, v.4, p.665-674, 1992.

BASKIN, J.M.; BASKIN, C.C. The annual dormancy cycle in buried weed seeds: a continuum. BioScience, v.35, p.492-498, 1985.
BÊDE, S.N.P. et al. Identificação de fatores nutricionais limitantes da fixação simbiótica do nitrogênio atmosférico em leucena. Revista Brasileira de Ciência do Solo, v.9, n.1, p.5-7, 1985.

BEWLEY, J.D.; BLACK, M. Seeds: physiology of development and germination. New York: Plenum Press, 1985.367p.

BORGES, E.E.L.; BORGES, R.C.G.; TELES, F.F.F. Avaliação da maturação e dormência de sementes de orelha de negro. Revista Brasileira de Sementes, v.2, n.2, p.29-32, 1980.

CARPENTER, W.J.; OSTMARK, E.R.; RUPPERT, K.C. Promoting rapid germination of needle palm seed. Gainesville: Florida State Horticultural Society, 1993. p.336-338.

CARVALHO, N.M.; NAKAGAWA, J. Sementes: ciência, tecnologia e produção. Jaboticabal: FUNEP, 2000. p.98-118.

FIRMINO, J.L.; SANTOS, D.S.B.; SANTOS FILHO, B.G. Características físicas e fisiológicas de sementes de cerejeira (Torresia acreana Ducke) quando as sementes foram coletadas do chão ou do interior dos frutos. Revista Brasileira de Sementes, v.18, n.1, p.28-32, 1996.

FOWLER, J.A.P.; BIANCHETTI, A. Dormência em sementes florestais. Colombo:

EMBRAPA Florestas, 2000. 27p. (Documentos, 40).

FOWLER, J.A.P.; MARTINS, E.G. Coleta de sementes. In: MANEJO de sementes de espécies florestais, Colombo: EMBRAPA Florestas, 2001. p.9-13. (Documentos, 58).

FOWLER, J.A.P.; STURION, J.A. Aspectos da formação do fruto e da semente na germinação da erva-mate. Brasília: EMBRAPA, 2000. p.1-5. (Comunicado Técnico, 45).

KOLLER, D. Environmental control of seed germination. In: KOLLER, D. Seed biology. New York: Academic Press, 1972. p.2-93.

R. Árvore, Viçosa-MG, v.28, n.5, p.655-662, 2004 
KOZLOWSKI, T.T.; KRAMER, P.J.; PALLARDY, S.G. The physiological ecology of woody plants. San Diego: Academic Press, 1991. 657p.

LARANJEIRA, F.F. Infestação de cochonilha pardinha em sansão-do-campo usado como cerca viva em pomares de laranja. Bragantia, v.56, n.2, p.289-290, 1997.

LORENZI, H. Árvores brasileiras: manual de identificação e cultivo de plantas arbóreas nativas do Brasil. 3.ed. Nova Odessa: Instituto Plantarum, 2000. v.1.351p.

MARTINS, C.C.; CARVALHO, N.M.; OLIVEIRA, A.P. Quebra de dormência de sementes de sabiá (Mimosa caesalpiniaefolia Benth.). Revista Brasileira de Sementes, v.14, n.1, p.5-8, 1992.

MOUSSA, H. et al. Factors affecting the germination of doum palm (Hyphaene thebaica Mart.) seeds from the semi-arid zone of Niger, West Africa. Forest Ecology and Management, v.104, p.27-41, 1998.

NAKAGAWA, J. Testes de vigor baseados no desempenho das plântulas. In: KRZYZANOWSKI, F.C.; VIEIRA, R.D.; FRANÇA NETO, J.B. Vigor de sementes: conceitos e testes. Londrina: ABRATES, 1999. p.2-15.

POPINIGIS, F. Fisiologia da semente. 2.ed. Brasília: ABRATES, 1985. p.19-95.

RIBEIRO, D.V. Programa de produção e tecnologia de sementes de espécies florestais nativas e exóticas desenvolvido pela Estação Florestal de experimentação agrícola Eng. Agr. Mário Xavier. In: SIMPÓSIO SOBRE TECNOLOGIA DE SEMENTES FLORESTAIS, 1. 1984, Belo Horizonte. Anais... Belo Horizonte: ABRATES, 1984. p.109118.
ROLSTON, M.P. Water impermeable seed dormancy. The Botanical Review, v.44, p.365-396, 1978.

SANCHEZ-BAYO, F.; KING, G.W. Imbibition and germination of seeds of three Acacia species from Ethiopia. S. African Journal Plant Soil, v.11, n.1, p.20-25, 1994.

SASAKI, S. Storage and germination of some Malayan legume seeds. Forestry, v.43, p.161$165,1980 \mathrm{a}$.

SASAKI, S. Storage and germination of dipterocarp seed. Forestry, v.43, p.290-308, 1980b.

TAO, K.L. Genetic alteration and germplasm conservation. In: FU, J.; KHAN, A.A. (Eds.). Advances in the science and technology of seeds. Beijing: Science Press, 1992. p.137-149.

TEKETAY, D. Germination ecology of two endemic multipurpose species of Erythrina from Ethiopia.

Forestry Ecology and Management, v.65, n.1, p.81-87, 1994.

TORRES, S.B.; FIRMINO, J.L.; MELLO, V.D.C. Germinação de sementes de sabiá (Mimosa caesalpiniaefolia Benth.) e algaroba (Prosopis juliflora (SW) DC). Ciência Rural, v.24, n.3, p.629-632, 1994.

VEASEY, E.A.; FREITAS, J.C.T.; SCHAMMASS, E.A. Variabilidade da dormência de sementes entre e dentro de espécies de Sesbania. Scientia Agrícola, v.57, n.2, p.299-304, 2000.

WILLAN, R.L. A guide to forest seed handling: with speed reference to the tropics. Rome: FAO, 1985. 379p. (FAO, Forestry Paper, 20/2). 